\title{
LOCALIZATION PROBLEM IN DISASTER MANAGEMENT SMARTPHONE APPLICATION
}

\author{
Awadhesh Kumar Maurya \\ IT Department, IET \\ Dr. Ram Manohar Lohia Avadh University, \\ Faizabad, UP(India)
}

\author{
Neeraj Kumar \\ DIT, SIST, \\ BBAU, Lucknow(India)
}

\begin{abstract}
During a flood disaster, its reporting is an important issue for the possible victims and similarly important about the place of disaster for the rescuers. One mobile application is in use for the disaster reporting using the same kind of concept, referred as MyDisasterDroid (MDD). This application helps to provide actual position of disaster to relief them and rescuers, but its improvement is possible through a correction in its methodology. This paper provides idea to make it better after point out its some common drawbacks. In this work, researcher showing the situations, in which, the formula to find correct location, used in MDD, has failed to give good result.
\end{abstract}

Keywords: Genetic Algorithm, Travelling Salesman Problem, MDD, Flood, Disaster.

\section{INTRODUCTION}

Recently, rainfall induced disasters including rainfall and landslide have claimed about 120 lives during 27 July 2016 to 31 July to $31^{\text {st }}$ July 2016 in Kathmandu region [1,2]. Statistics reveals due to rainfall induced disaster at various places, India has lost overall 89 lives in the year 2016. Generally, during the flood all the paths going out from affected area are blocked hence victims have no option but to stuck. In addition, communication failure makes the situation far worst. This is the reason victims are not able to even communicate with each other to find out the ways to go outside the affected area. MDD developed by Fazardo et al $[3,4,5]$ can work better in this situation as the authors claim. This Application finds optimal route between locations using genetic algorithm with specific formula. As Disaster Management includes four phases namely planning preparedness, Mitigation and Response/ Recovery, the App works in Response phase. This phase of disaster management includes search and rescue operations as well as provision of emergency relief. The phase requires efficiency as time is of much importance in this kind of situation. Delay of even a second may claims many lives. Thus a system that determines the most optimum route for the volunteers and rescuers in order to serve the most of the people and provide maximum coverage of the affected area in the shortest possible time is beneficial. Though the App is very useful, but it fails to address the work in this paper, address few shortcomings of the app and adds some functionality to make it feature rich.

\section{RELATED WORK}

To help during disasters, mobile technology plays an important role for providing communication through connectivity between devices or through voice call / chat between devices. During disaster, communication setup generally goes down due to the failure of infrastructure network setup. Hence, in absence of infrastructure network, the mobile technology and Adhoc networks may play important role. Some tools have been developed to overcome the problem. Let us have a little sight on these tools:

Smartphone apps for Disaster: Various kinds of apps have been developed for different OS including Android, BlackBerry, iPhone, iPad etc. few of them are helpful victims and few are for rescuers. However, some apps are useful to both for rescuers as well as for possible victims. Table 1 list out some apps helpful for rescuers whereas table 2 lists out some apps helpful for victims.

Table 1: Apps Helpful for rescuers

\begin{tabular}{|c|c|c|}
\hline APP & USE & \\
\hline FEMA [6] & $\begin{array}{l}\text { Provides: } \\
\text { - } \quad \text { Preparedness information for various disasters, } \\
\text { - } \quad \text { Disaster Recovery Center locations and shelters. }\end{array}$ & \\
\hline ELERTS App [7] & $\begin{array}{l}\text { Reports disaster event, } \\
\text { Allows users to: } \\
\text {-Know about event type, } \\
\text {-Send photo within group, } \\
\text { Useful for field data collection. }\end{array}$ & \\
\hline HelpMe [7] & $\begin{array}{l}\text { Builds ad hoc network using Wi-Fi to enable Smartphone } \\
\text { information to next hop. }\end{array}$ & to send \\
\hline POSIT [8] & $\begin{array}{l}\text { Works with the phone's GPS, camera, database, and touch } \\
\text { to collect and save data of disaster victims and transmit this }\end{array}$ & $\begin{array}{l}\text { screen } \\
\text { data to }\end{array}$ \\
\hline
\end{tabular}




\begin{tabular}{|c|c|}
\hline & remote server using Internet or \\
\hline \multicolumn{2}{|r|}{ Table 2: Apps Helpful for victims } \\
\hline APP & USE \\
\hline WISER [9] & $\begin{array}{l}\text { Provides information on biological, chemical and } \\
\text { threats. }\end{array}$ \\
\hline $\begin{array}{l}\text { Shelter Finder } \\
{[10]}\end{array}$ & $\begin{array}{l}\text { - Displays shelter information from the National Shelter } \\
\text { (NSS) in U.S. }\end{array}$ \\
\hline Preparis [10] & $\begin{array}{l}\text { Provides expert information, response rules, communications } \\
\text { training for disasters. }\end{array}$ \\
\hline ubAlert [10] & $\begin{array}{l}\text { A Social network compatible with e-mail, twitter and Facebook. } \\
\text { - } \\
\text { - }\end{array}$ \\
\hline $\begin{array}{l}\text { Earthquake-ARC } \\
\text { [11] }\end{array}$ & $\begin{array}{l}\text { - } \quad \text { Provides instructions on what to do before/ during/ after } \\
\text { earthquake. } \\
\text { - } \quad \text { Provides "I'm Safe" feature to notify family. }\end{array}$ \\
\hline $\begin{array}{l}\text { Hurricane } \\
\text { byARC[11] }\end{array}$ & $\begin{array}{l}\text { Provides access to local and real time information on what } \\
\text { before, during and after hurricanes. } \\
\text { - } \\
\text { Provides "I'm safe" feature to notify family. }\end{array}$ \\
\hline $\begin{array}{l}\text { Tornado } \\
\text { [11] }\end{array}$ & $\begin{array}{l}\text { - } \quad \text { Issues Tornado Warning \& Alert. } \\
\text { - } \quad \text { Suggestions to prepare for a tornado based on interactive } \\
\text { and simple step-by-step advice. }\end{array}$ \\
\hline $\begin{array}{l}\text { Wildfires ARC } \\
{[11]}\end{array}$ & $\begin{array}{l}\text { - } \quad \text { Issues wildfire warnings, } \\
\text { - } \quad \text { Issues "Blaze Alerts" to notify new wildfire, } \\
\text { perimeter. }\end{array}$ \\
\hline $\begin{array}{l}\text { ARC: } \\
\text { ShelterView [11] }\end{array}$ & $\begin{array}{l}\text { Maps the locations and shelters from American Red Cross } \\
\text { National Shelter System (NSS). }\end{array}$ \\
\hline SOS Android 11] & $\begin{array}{l}\text { Provides step-by-step video narration. } \\
\text { - } \quad \text { Allows people to quickly respond to emergency }\end{array}$ \\
\hline
\end{tabular}

In addition, few more apps have been identified to help victims as well as rescuers. The apps are enlisted in table 3 . All the apps either used by rescuer, or by victims or by both are generally connected through internet or Adhoc networks.
Apps which are using internet facility as a basic requirement may be useful to minimize risk using disaster preparedness by issuing alert.

Table 3: Helpful apps for Victims and Rescuers

\begin{tabular}{|c|c|}
\hline APP & USE \\
\hline $\begin{array}{l}\text { Disaster } \quad \text { Alert } \\
\text { [11] }\end{array}$ & $\begin{array}{l}\text { - Provides an interactive map of Active Hazards occurring } \\
\text { the globe. }\end{array}$ \\
\hline Radar Now [12] & $\begin{array}{l}\text { Provides National Weather Service (NWS) images from } \\
\text { NOAA WSR-88D NEXRAD Radar sites. }\end{array}$ \\
\hline WeatherBug[12] & Forecasts weather information. \\
\hline Essentials & $\begin{array}{l}\text { Navigates, manages waypoints, tracks, routes, and builds } \\
\text { dashboard from } 45 \text { widgets. }\end{array}$ \\
\hline $\begin{array}{l}\text { Backpacker GPS } \\
\text { Trails Lite [12] }\end{array}$ & $\begin{array}{l}\text { Uses offline maps for navigation. } \\
\text { No cell signal needed. }\end{array}$ \\
\hline $\begin{array}{l}\text { SOS } \\
{[12]}\end{array}$ & $\begin{array}{l}\text { - Sends a user's GPS coordinates to a predefined list of people in } \\
\text { emergency. }\end{array}$ \\
\hline $\begin{array}{l}\text { MDD } \\
{[3,4,5,13]}\end{array}$ & $\begin{array}{l}\text { MDD works on the basis of geo location to provide help to Victims } \\
\text { and Rescuers both. }\end{array}$ \\
\hline
\end{tabular}

Apart from these apps, researchers are continuously trying to provide better way to detect the disasters and issue fast alert.

\section{THEORY USED FOR MDD}

To provide best possible route to rescue, MDD uses Travelling Salesman Problem (TSP) and Genetic algorithm along with Geo-location just as per MDD.

Travelling salesman problem (TSP)

To find out a route for water flow in order to avoid flood or excess amount of stored water at a place, researchers have used the concept of travelling salesman problem. The travelling salesman problem is a permutation problem with the objective of finding the path of shortest length on an undirected graph that represents cities as nodes to be visited. The concept of travelling salesman is that the travelling salesman starts from a node, visits all other nodes successively only one at a time, and finally returns to the starting node. 
TSP for MDD: In the work of Fazardo et al, TSP has been assumed to calculate the distance between two points in MDD. In this they were use Euclidean formulae to find distance however indicated formulae in their paper is not doing work well for few situations described in section IV in this article.

\section{Genetic Algorithms}

GA in MDD: Genetic algorithm has been used by MDD to generate initial solution. This algorithm provides the initial solution after taking location as an input for the algorithm. MDD works on the basis of concept of geo-location to provide inputs to the genetic algorithm. It finds points of location, using application installed in MDD for sending location via text or SMS to MDD. Based on TSP, distances between locations are calculated. MDD uses GA with flow diagram used in it [5] not having the possibility to detect the failed route in disaster that is a big possibility. Failed route by the disaster initialization is a big problem for every disaster. It is sometimes a big problem. MyDisasertDroid can use GA [14] efficiently after removal of possible damaged routes in initial steps before start of GA.

In disasters, especially in rainfall triggered type, routes are generally damaged or blocked. These routes are not having important until its reinstallation for use. MDD installed on Android OS uses google map to show its feature MapView. MapView provides different map images like satellite view, street view and traffic view. Due to different kind of delays google map is unable to provide real time images so MyDisasterDoid also have more delay that is important in disaster management. This delay is the basic reason of inefficiency to provide real time picture of incident. MDD provides the facilities of dynamic recalculation of route based on calculation for TSP using Euclidean distance formula in equation 1 discussed by fazado [5]. But this concept has several problems to use Euclidean formula for the situation like a disaster. Though, sometimes this concept works efficiently but in case of rainfall induced disaster or in landslide it has probability of route failure due to cause of route damage. In landslide or rainfall induced disaster path break or defected path are generally a big problem. Euclidean distance formula can provide better distance between two points when it will use with the sea height and slope of location with algorithm in some steps.

\section{Use of Geo-location in MDD:}

To find a geographic location of victim there is a need to find the coordinate of this place in general. MDD provides two application, in which first is the position of installed application on android i.e. MDD and second by sending location via text or SMS to MDD. World Geodetic System 84 or WGS84 used by GPS to find geolocation also implemented in android OS. WGS 84 helps to find distance between geolocations that is further used by MDD.

I.

Problem Statement

\section{Challenges for System implementation:}

In case of flood, choice of Mechanism or method to find accurate location is the problem that is faced to implement the system. Problems are quite large, due to the no quick way to find possible direction about expansion of flood water while MDD also having few drawbacks.

\section{Claim: Difficulties with Fazardo's App MDD}

Fazardo and opus uses formula to find out the distance, and written term in their work [5], in equation (1).
The Euclidean distance $d$, between any two cities with coordinates (x1, yl) and $(\mathrm{x} 2, \mathrm{y} 2)$ is calculated by:

$$
d=\sqrt{|x 1-y 1|^{2}+|x 2-y 2|^{2}}
$$

But in no consideration about Euclidian plane, this formula is not applicable as cases considered. Formula is not working correctly as per our assumption which is proved with different readings. This equation is unable to provide distance accurately for some below discussed values in graphs.

\section{Geometrical validation of problem}

Few geometrical situation validates the problem statement that can understand through measuring the distance between different coordinates by formulae given by Fazardo et al[5].

(a) Geographically: let us a location on different coordinate:

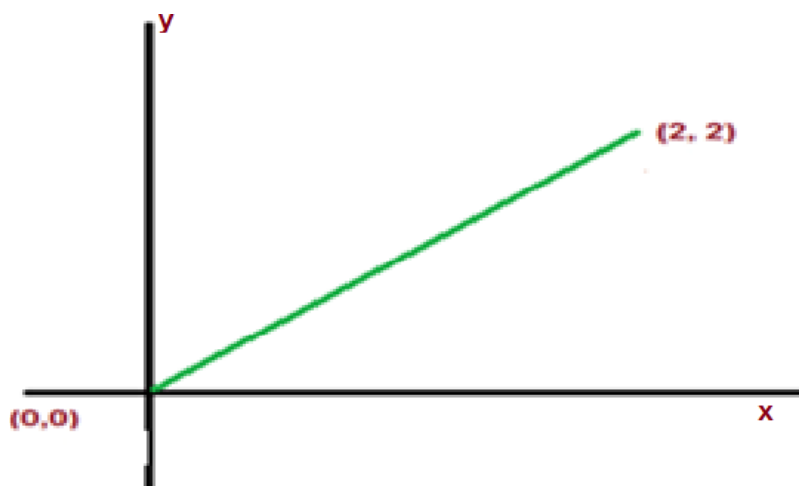

Figure 1: To calculate distance (a)

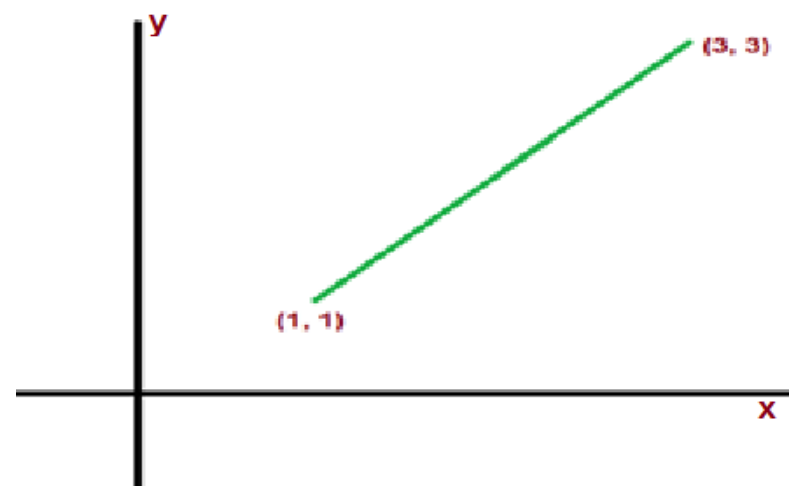

Figure 2: To calculate distance (b)

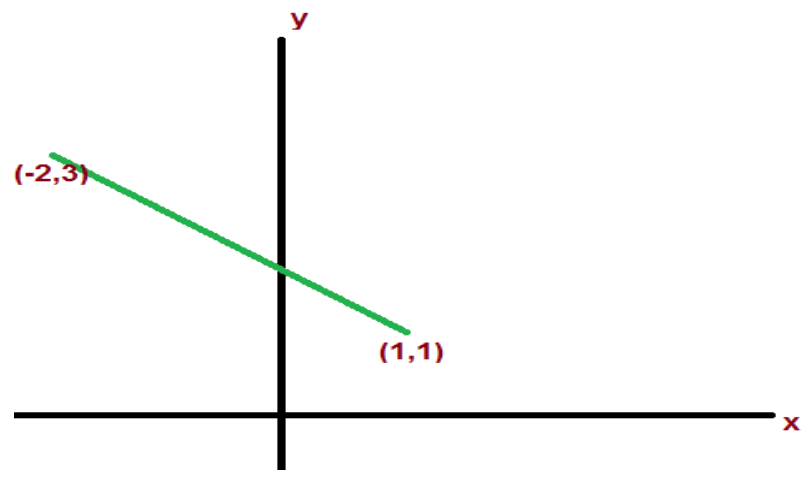

Figure 3: To calculate distance (c) 
After applying Fazardo's equation, let us $(1,1)$ and $(3,3)$ as $\left(\mathrm{x}_{1}, \mathrm{y}_{1}\right)$ and $\left(\mathrm{X}_{2}, \mathrm{Y}_{2}\right)$ then find out the distance by (1)Fazardo’s written formula, and by (2) Euclidien formula, values are provides different results. :

\section{CONCLUSION}

On the basis of analysis of graphs we can say, in disaster management system, accuracy and time consumption of processing sometimes may be crucial. MDD provides map view through the Google map. But in this Google map or MDD not provide any information about failed route. It means with the all discussion we can say MDD can be better after removal of some problems of the MDD.

Change in the formula discussed by Fazardo et al [5].

\section{REFERENCES}

[1] At least 39 dead in floods, landslides across country, The Kathmandu Post, Vol XXIV No 160, 27 July 2016.

[2] Asia -Severe weather events, Emergency Response Coordination Centre (ERCC) -ECHO Daily Map, European commission Europian Union| 01/08/2016.

[3] Jovilyn Therese B. Fajardo and Carlos M. Oppus, "Implementation of An Android-Based Disaster Management System”, Recent Advances in Electronics, Hardware, Wireless and Optical Communications, Issn: 1790-5117, pp:126-130.

[4] Jovilyn Therese B. Fajardo and Carlos M. Oppus, "A Mobile Disaster Management System Using The Android Technology”, International Journal of Communications, Issue 3, Volume 3, 2009, pp: 77-86.
[5] Jovilyn Therese B. Fajardo and Carlos M. Oppus, A Mobile Disaster Management System Using The Android Technology, WSEAS Transactions on Communications, issue 6, Volume 9, June 2010, issn: 1109-2742, pp: 343-353.

[6] Shayne Adamski, Jonathan R. Cantor, Privacy Impact Assessment for the FEMA Smartphone Application with Disaster Reporter Feature, Homeland Security, July 29, 2013

[7] Swanil R. Rajput, Mohd. Sohel Deshmukh, Karbhari V. Kale, Cross-platform Smartphone Emergency Reporting Application in Urban Areas using GIS Location based and Google Web Services, International Journal of Computer Applications (0975-8887), Volume 130 -No. 12, November 2015.

[8] Antonio Alcorn, Gong Chen, Christopher Fei, Qianqian Lin, POSIT: Free Search \& Rescue Tool, The humanitarian FOSS Project, 2009.

[9] WISER user's Guide- version 5, by National Library of Medicine, 30/09/2016.

[10] http://www.croplife.com/editorial/matt- hopkins/10-bestapps-for-emergency-preparedness/: 30/09/2016

[11] http://www.disaster-relief.org/disaster-mobile-apps.htm 04/09/2016.

[12] http://blog.emergencyoutdoors.com/android-phone-apps-forthe-outdoors/: 04/09/2016.

[13] R.Rajalakshmi, Dr. R.Periyasamy, "A Mobile Disaster Management System Using the Android Technology", International Journal of Innovative Research in Advanced Engineering (ijirae) issn: 2349-2763, issue 12, volume 2 (December 2015), pp: 7-12

[14] Rahul Malhotra, Narinder Singh \& Yaduvir singh, "Genetic Algorithms: Concepts, Design for Optimization of Process Controllers”, Computer and Information Science vol. 4, no. 2; March 2011, Canadian Center of Science and Education, pp:39-54, ISSN 1913-8989. 